\title{
EVOLUCIÓN HISTÓRICA DE ALFA: UN GRUPO ECONÓMICO DE CAPITAL NACIONAL
}

\author{
Beatriz Pérez Sánchez*, Armando Mayo Castro**, Jenner Torrez Vázquez ${ }^{\star \star *}$
}

\begin{abstract}
Pérez-Sánchez B., A. Mayo-Castro A., Torrez-Vázquez J. Evolución histórica de ALFA: un grupo económico de capital nacional Hitos de Ciencias Económico Administrativas 2015;21 (59): 19-32
\end{abstract}

\section{RESUMEN}

Objetivo: Conocer la evolución histórica de una gran empresa de capital nacional y analizar las estrategias que ha puesto en práctica desde su fundación hasta constituirse en un gran corporativo o grupo económico. Se parte del enfoque del devenir histórico en el que prevalece el análisis de los orígenes y evolución de la empresa. Por ende predomina la crónica y las descripciones, reúne acontecimientos de la vida nacional y local de Monterrey, con la guía de un orden cronológico, logrando establecer planteamientos analíticos.

Material y método: Los métodos que se utilizaron fueron el método histórico-crítico, el método analítico con un enfoque dinámico y el método comparativo. Se utilizaron los enfoques: 1) regional, 2) de origen histórico, y 3) de estrategias corporativas y organizaciones. El enfoque regional considera que el origen regional es un factor importante en las prácticas económicas y políticas de los empresarios mexicanos. El segundo da mayor peso al origen histórico y a las condiciones de surgimiento para establecer la configuración definitiva, las prácticas económicas y políticas predominantes y el patrón de desarrollo del grupo. El tercer enfoque de las estrategias corporativas y organizacionales, atiende la cambiante estructura organizativa de las grandes corporaciones modernas y su tendencia a adoptar estructuras de administración y morfologías corporativas más complejas. Se establece el método comparativo para tener en cuenta aquellas
Pérez-Sánchez B., Mayo-Castro A., Torrez-Vázquez J. Historical evolution of alfa: an economic group of national capital Hitos de Ciencias Económico Administrativas 2015;21 (59): 19-32

\section{ABSTRACT}

Objective: Know the historical evolution of a large national capital firm and analyze the strategies that have been implemented from its foundation to its constitution as a solid corporation or economic group. The study starts with the historical approach where the origins and evolution of the company prevail. Thus, chronic and descriptions predominate. It gathers events of the national life and the local life of Monterrey, with the guidance of a chronological order, managing to establish analytical approaches.

Material and method: The methods that were used were the historical-critical method, the analytical method with a dynamic approach and the comparative method. The approaches that were used were: 1) the regional approach, 2) the historical origin approach, and the corporate and organizational strategies approach. The regional approach considers that the regional origin is an important factor in economic and political practices of Mexican businessmen. The second approach gives greater weight to the historical origin and emergence conditions to establish the final configuration, the prevailing economic and political practices and the pattern of group development. The third approach of corporate and organizational strategies, addresses the changing organizational structure of large modern corporations and their tendency to adopt corporate management structures and more complex corporate morphologies. The comparative method is established in order to take into account situations where common

\footnotetext{
* Doctora en Economía. Profesora-Investigadora de la División Académica de Ciencias Económico Administrativas (DACEA), Universidad Juárez Autónoma de Tabasco (UJAT).

** Dr. en Finanzas Públicas. Profesor-Investigador DACEA-UJAT.

*** Estudiante de la Licenciatura en Economía DACEA-UJAT.
}

Fecha de recibido: 18 de noviembre de 2014. Fecha de aceptación: 16 de diciembre de 2014. 
situaciones en que las características comunes de las empresas se combinan con circunstancias históricas que preceden a la formación de grandes corporativos en Monterrey.

Resultados: No se pretendió hacer un análisis histórico profundo, sino identificar y reconocer los eventos históricos y particularidades del comportamiento empresarial en Monterrey a fin de rescatar una presencia socioeconómica activa que llevará a considerar el surgimiento de un gran corporativo o grupo económico que ha transitado a la lógica nacional. Se investigó a ALFA desde sus orígenes y constitución como empresa en 1973 hasta 1982. Al periodo comprendido entre 1890 y 1910 se le puede considerar como la primera etapa de surgimiento de las grandes empresas manufactureras en México, período que corresponde al porfiriato. El patrón de inversiones que predominó dio como resultado una gran concentración del capital en los sectores de ferrocarriles, minería y banca, aunque también en algunas empresas del sector industrial como Cervecería Cuauhtémoc del cual nació ALFA. En Monterrey surgieron en esta época grandes empresas que todavía subsisten y son la base de varios grupos o corporativos industriales actuales.

Conclusiones: El nacimiento industrial de Monterrey es el resultado lógico de un proceso de acumulación de capital dentro del ámbito comercial y de la necesidad de esos capitales de hallar nuevos campos de aplicación que posteriormente invirtieron en la esfera industrial. Los factores a los que podemos atribuir el desarrollo industrial de Monterrey corresponden al apoyo permanente del Estado, a factores geográficos favorecedores y a coyunturas históricas de México.

Una segunda etapa de periodización de las grandes empresas se localiza en los años que van de 1930 a 1950 y se caracteriza por la instalación de empresas dedicadas a sustituir importaciones y la producción orientada hacia un mercado nacional y donde el Estado orientó el proceso de desarrollo. En una tercera etapa que va de 1951 a la década de 1970 se da propiamente el surgimiento del grupo económico de ALFA cuando sus inversiones se dirigen hacia la integración tanto horizontal como vertical y la diversificación en la producción de las empresas, así como la suscripción en la Bolsa de Valores. characteristics of companies are combined with historical circumstances preceding the formation of large corporations in Monterrey.

Results: There was no intention to make a deep historical analysis, but to identify and recognize the historical events and particularities of corporate behavior in Monterrey in order to rescue an active socioeconomic presence that will lead to consider the emergence of a great corporate or economic group that has transited to national logic. Alfa was studied from its origins and constitution as a company in 1973 until 1982. The period from 1890 to 1910 can be considered as the first stage of the emergence of great manufacturing companies in Mexico, and this period belonged to the Porfiriato. The predominant pattern of investments resulted in a large concentration of capital not only in the sectors of railways, mining and banking, but also in some industrial companies such as Cerveceria Cuauhtemoc from which ALFA was born. In Monterrey large companies emerged in that time, and they still subsist nowadays as the basis of several current industrial groups or corporates.

Conclusions: The industrial birth in Monterrey is the logical result of a process of capital accumulation within the commercial environment and the need for those capitals to find new application fields that later invested in the industrial sphere. The factors that we can attribute to the industrial development of Monterrey correspond to the permanent support of the State, the beneficial geographical factors and the historical junctures of Mexico.

A second stage of periodization of large companies is located between the years 1930 and 1950 and it is characterized by the establishment of companies devoted to substitute importations and the production oriented towards the national market, where the State led the development process.

In a third stage that goes from 1951 to the 1970's the emergence of the economic group ALFA is really done when its investments are led towards the horizontal and vertical integration and the diversification in the production of the companies, as well as the subscription to the stock market.
Palabras clave: Corporativos. Grandesempresas. Grupo económico. Integración vertical. Historia económica.
Key words: Corporates. Large companies. Economic group. Vertical integration. Economic history.

DIRECCIÓN PARA RECIBIR CORRESPONDENCIA: Correo electrónico: beatrizperez10@hotmail.com 
I estudio sobre las grandes empresas industriales en México, requiere criterios metodológicos que permitan considerar los comportamientos económicos observables de estas grandes empresas o corporativos, en lo que se refiere a sus características y situación actual así como a sus cambios en cada etapa histórica, de tal forma que se las conciba como organizaciones jerárquicas que evolucionan a partir de factores y condiciones propias, así como por factores de su entorno institucional y político nacional, por las condiciones de las industrias y sectores donde concurren las empresas, es decir considerar la interrelación nacional, internacional y de la economía global.

Para Celso Garrido y Wilson Peres(1998), el concepto de grupo económico implica un conjunto de empresas operativamente independientes que son coordinadas por un ente central. Sus actividades pueden estar concentradas en un cierto tipo de producto, diversificadas a lo largo de una cadena productiva con integración vertical u organizada en conglomerados que operan en varios sectores de actividad económica. Muchas veces, estas formas organizativas incluyen instituciones financieras, las que en algunos casos son la entidad dominante para determinar los objetivos comunes. En general, los grupos económicos en América Latina surgieron al calor de la industrialización sustitutiva de importaciones. La aplicación de programas de reforma estructural ha redefinido su espacio dentro de sus respectivas economías, lo cual ha generado trayectorias divergentes - expansión/ achicamiento- especialización/diversificación.

El grupo burgués regiomontano transitó por un proceso de acumulación originaria de capital, su actividad cotidiana condicionada por el momento histórico le permitió una concentración de dinero y de bienes, antes de transformarse en controlador directo de actividades productivas, tendiendo a transformarse en clase social justamente cuando inició su traslado masivo de capitales a la producción capitalista a partir de 1890 en un movimiento que usufructuó las condiciones generadas por el porfiriato, las nuevas vinculaciones que se planteaban con la economía internacional y la estructuración y ampliación del mercado interior y la producción en gran escala de bienes dedicados al propio proceso productivo, con base en la industria pesada(Cerutti, 1992).

\section{El porfiriato: surgimiento de grandes empresas}

El capital y el capitalismo como sistema productivo fueron los que tendieron a imponer su hegemonía a la política económica que caracterizó al porfiriato. Una política que intentó saturar amplios espacios del Estadonación que se afirmaba. Los núcleos burgueses -dueños del capital, gestores del capitalismo- fueron los que dieron sustento a la política global de crecimiento económico que Díaz propició en estrecha alianza con el inversionista extranjero que traía recursos, tecnología, fuerza de trabajo especializada y una forma de organización empresarial que echó raíces en el país.

Entre 1870 y 1910 se multiplicaron las grandes empresas modernas, distintos procesos operaron al mismo tiempo: 1) La ampliación de los mercados regionales y el creciente proceso de vinculación entre los mismos; 2) Las nuevas corrientes de inversiones extranjeras desde el decenio de 1880; 3) El desarrollo de mercados de capitales locales; y 4) La creación de nuevos marcos institucionales para las actividades económicas. Todos estos procesos contribuyeron al nuevo panorama que permitiría una aceleración del desarrollo capitalista en el país.

Entre las primeras grandes empresas modernas establecidas en México en el último cuarto siglo del XIX es frecuente citar en orden de prioridad a las compañías ferroviarias ya que eran las mayores compañías del porfiriato en términos de capitales y también en volumen y extensión de actividad. En su mayoría estas compañías nacieron grandes y desde un principio, adoptaron modos organizativos que eran similares a sus contemporáneas en los Estados Unidos, por ejemplo se refiere en particular a los Ferrocarriles Central (1880) y Nacional (1882) que crearon las primeras redes de transporte moderno en el centro-norte del país. Distinto es el caso del Ferrocarril Mexicano (1873) que conectaba el puerto de Veracruz con la ciudad de México, financiado en parte con capital británico y con capitales locales (Marichal, 1997).

Nuevas condiciones en la minería, las comunicaciones y la propiedad de la tierra, alteraron la evolución del norte de México. El aspecto más impresionante fue sin duda el crecimiento de la gran propiedad en toda la República. La legislación agraria de la reforma liberal de 1856-1857, había empezado el proceso al transferir a manos privadas vastas propiedades eclesiásticas y corporativas, la enajenación de los terrenos baldíos por el Estado y por medios privados, la de las tierras comunales de los indios (Carr, 1973). La zona norte, registró un importante crecimiento económico. La extensión de los ferrocarriles favoreció la minería en gran escala (42.39\% de la producción nacional en 1907) y la producción agropecuaria en grandes extensiones y utilizando métodos modernos de cultivo. En 1908, las fábricas y talleres regiomontanos generaron valores 
superiores en casi nueve veces a los registrados en la agricultura, una de las tradicionales bases productivas de Nuevo León. En 1910, el agro alcanzó sólo el 19\% de los valores gestados por la metalurgia pesada y la siderurgia, que ya funcionaban en Monterrey (Cerutti, 1992). Por ende, el dato vertebral que caracterizó a Monterrey, no fueron las fábricas de bienes ligeros y de consumo masivo, sino la producción de bienes e insumos destinados a la misma producción (Ceruttti y Valdaliso, 2003).

Entre 1890 y 1910 se dió una marcada diversificación de las inversiones que pusieron en marcha tanto industrias dedicadas a abastecer el consumo productivo (grandes fundiciones, cemento, vidrio) como el consumo personal (cerveza y otras bebidas, textiles, artículos para higiene, materiales para la construcción, alimentos elaborados), el ramo minero, el crédito y los bancos, la propiedad y explotación de la tierra, los servicios y el transporte.

El origen de Alfa no se explica sin considerar la creación de la Fábrica de Cerveza y Hielo Cuauhtémoc, que fue fundada el 16 de diciembre de 1890, Isaac Garza y J.M. Schneider pidieron al Estado una concesión para la creación de una fábrica de vidrio y de cerveza de exportación que comenzó a operar a finales de 1891 y es el origen directo de Femsa.

\section{Los años veinte}

El periodo posrevolucionario de 1921 a 1930 fue de esfuerzos institucionales para convertir al país de minero, petrolero y agropecuario, en un país en proceso de industrialización. La cervecería Cuauhtémoc inauguró a mediados de los veinte un ciclo de integración productiva, de reorganización operativa y de expansión en el plano de la distribución destinado a conquistar porciones sustanciales del mercado interno. En la Cervecería Cuauhtémoc los primeros pasos en materia de diversificación productiva incluyeron la instalación dentro de la cervecería de: a) una fábrica de gas carbónico (insumo utilizado para tornar más espesa la espuma); b) el departamento de cajas de cartón corrugado; c) el departamento de elaboración de tapones corona y de envases metálicos; y d) una fábrica de malta.

Posteriormente, en un proceso de expansión, se planteó que las actividades que no mantenían relación exclusiva con la elaboración de cerveza se manejaran como sociedades anónimas independientes y bajo nombres distintos. El objetivo era facilitar su desarrollo y ampliar las ventas. Así, en 1929 surgió Fábricas Monterrey S.A. de C.V., (FAMOSA) que se inició con la producción de corcholatas, creció y expandió su producción para incluir envases metálicos, fue separada la factoría de cajas de cartón. Casi $85 \%$ de sus acciones quedó en manos de Cervecería que le traspasó terrenos, edificios y maquinaria requerida para su funcionamiento. Para su instalación recibió una concesión de veinte años: por ser «industria nueva», conforme a la ley estatal de diciembre de 1927 sobre protección a la industria, pagaría sólo $25 \%$ de los impuestos locales. Además, en ese mismo año el gobierno del estado de Nuevo León profundizó una legislación existente desde 1888, la Ley sobre Protección a la Industria ${ }^{1}$, favorable al capital y al específico desarrollo industrial, ley que se anticipó con claridad a las que a escala nacional se sancionarían en los años treinta y cuarenta. Este ordenamiento declara el fomento industrial como de «utilidad pública». A diferencia de los decretos anteriores, las franquicias se otorgaban no sólo a industrias nuevas sino también a aquellas que ampliaban su tamaño, capital o número de trabajadores. Se concedían hasta por veinte años, eximiendo el $75 \%$ de los impuestos estatales y municipales.

\section{Los años treinta: la tendencia a la integración industrial}

En 1934 una nueva legislación también favoreció a las grandes empresas: la Ley sobre Franquicias a la Constitución de Nuevas Sociedades Anónimas². Esta Ley beneficiaba exclusivamente a las sociedades industriales o las que fomentaran la industria en Nuevo León y eximía del pago del $75 \%$ de los derechos de inscripción (en el Registro Público de la Propiedad) a los inmuebles en que se montara la fábrica o el organismo de fomento industrial. Gracias a esta legislación la expansión que se manifestó a partir de mediados de los treinta, incluyendo modalidades que se acentuarían en la década de los cuarenta, influenció: 1) La tendencia a la integración industrial; 2) La puesta en marcha de plantas productivas en diferentes lugares del país y en algunos casos en el exterior. A esta integración industrial se le conoció, como empresasmadre, posteriormente holding (y los grupos que impulsaron) intensificaron su ciclo de adaptación al nuevo régimen político, superando la crisis de1929 y comenzaron a usufructuar el aparato de protección, subsidios, concesiones, créditos y consumo dirigido que permitía un Estado dedicado a estimular la industrialización de México (Cerutti, 2000). El caso más conocido y popular fue Cervecería Cuauhtémoc, que

\footnotetext{
'Periódico Oficial del Estado de Nuevo León, 3 de diciembre de 1927.

2 Periódico Oficial, 16 de mayo de 1934.
} 
desde 1921 comenzó a transformar sus departamentos internos en empresas autónomas.

En México, las décadas del 30 al 40 fueron de crisis económica y financiera. No obstante, el cuerpo principal del aparato financiero en Monterrey se estableció en el despegue industrial de estas décadas. En ese periodo se fundaron no menos de 28 instituciones financieras y de crédito; los bancos entraron al mercado de acciones y bonos con el fin de satisfacer las necesidades de inversión de capital en la industria y el comercio regionales (Vellinga, 1988). El desarrollo de los grupos Alfa y Cydsa, así como gran parte de la expansión de los grupos Cuauhtémoc y Vidriera, se produjo después de 1940, pero ya para mediados de la década de los treinta la familia Garza Sada constituía un grupo inversionista bien definido y dos de sus cuatros grupos económicos principales ya existían como entidades cohesivas. La familia Garza Sada no puede considerarse típica, sin embargo proporciona un ejemplo de un grupo económico porfiriano que sobrevivió la revolución para llegar a ser un grupo económico, parte de un segmento de la clase dominante (Hamilton, 1983).

\section{Los años cuarenta y cincuenta: la sustitución de importaciones y el desarrollo estabilizador}

El crecimiento hacia fuera se extiende desde la independencia hasta la gran depresión de 1933, coyuntura que marca el viraje al modelo de desarrollo hacia adentro. Más aún el viraje del modelo de desarrollo se da entre la depresión y el final de la guerra (Pinto, 1991). La coyuntura de guerra, la escasez de manufacturas importadas y la ampliación del mercado interno tornaron cada vez más necesario en México, la producción interna de bienes transformados. Entre 1940 y 1980 se dio en México un nuevo modelo económico la Sustitución de importaciones que se caracterizó por tener su base en el proteccionismo económico y en la significativa participación estatal en un considerable número de ramas de la economía. En los años cuarenta, México consideró que debía industrializarse para acelerar su paso e ingresar en el conjunto de países llamados "desarrollados». El proceso de industrialización que se inició entonces requería el fortalecimiento de una industria intermedia que llevara, poco a poco, a fabricar en México todo lo que hasta ese momento se tenía que importar en el extranjero. Ese es el comienzo del proceso llamado sustitución de importaciones (Puga, 1995). Llegar a ese punto implicó llevar a cabo tareas pendientes de la Revolución mexicana y convertir al Estado en el pivote del crecimiento económico. La reforma agraria cardenista, la expropiación petrolera, la nacionalización de los ferrocarriles, la creación de Nacional Financiera, del
Instituto Politécnico Nacional y de otras instituciones, fueron las bases que se necesitaban para dar ese impulso al proceso industrializador.

El modelo proteccionista funcionó satisfactoriamente durante varias décadas, numerosas empresas se fundaron y crecieron a lo largo del periodo. En Monterrey, la industrialización siguió esta pauta durante las décadas de los cincuenta y sesenta. Los sectores dedicados a los metales y a la metalurgia que trabajaban a su máxima capacidad, recibieron un fuerte impulso, produciendo insumos para la industria bélica norteamericana. Surgieron o se desenvolvieron así numerosas empresas ligadas a la metálica básica, los minerales no metálicos, la fabricación de productos metálicos y eléctricos, y el abastecimiento de energéticos entre otros ramos (Vellinga,1988).

El verdadero despunte modernizador e innovador de proyectos económicos se da en estos años cuarenta, cuando se inicia en México la segunda etapa del desarrollo de la siderurgia. En 1943 se funda Hojalata y Lámina (HYLSA), la cual inició con 179 trabajadores y 3 millones de pesos de capital. El objetivo era abastecer en forma autosuficiente a su «empresa madre», Cervecería Cuauhtémoc, S.A., del acero necesario para la fabricación de corcholatas, en respuesta a las fluctuaciones del mercado que dificultaban el abastecimiento de chatarra una vez que el metal se había agotado por los requerimientos bélicos de la segunda guerra y ante la necesidad imperativa de aumentar y diversificar la producción nacional de hierro y acero. En sus comienzos, Hojalata y Lámina fue una empresa de transformación dedicada a la producción de acero, la lámina producida era de una calidad tan baja que no se llegó a emplear para la fabricación de corcholatas. Todo el equipo con que empezó a operar fue adquirido en los Estados Unidos y era de segunda mano; en realidad mucho del equipo estaba considerado en aquel país como desecho. Durante el primer año la producción fue apenas de 4,300 toneladas (Sada,1973).

Para el año de 1948, la empresa produjo su propio acero con el uso de hornos eléctricos y a partir de la chatarra, registrando una producción anual de 20,000 toneladas. No obstante, en ese entonces, el único proceso conocido para reducir el mineral y convertirlo en materia prima para la producción de acero era el alto horno, pero la inversión inicial era sumamente alta y sus escalas de producción eran tales, que en aquella etapa la empresa no podía transformar productos acabados.

De Canadá y después de los Estados Unidos se importaron patentes para la producción de fierro esponja 
por medio de la reducción directa, aunque éstas nunca habían sido probadas a escala industrial y no llegaron a resultados satisfactorios, por tal motivo los técnicos de Hojalata y Lámina dejaron de lado las patentes extranjeras y siguieron investigando por su cuenta hasta llegar al proceso «HyL», un sistema de reducción directa para la producción de fierro esponja. El proceso consiste en la desoxidación del mineral por medio de gases reductores obtenidos del vapor de agua y gas natural, bajo ciertas condiciones de presión y temperatura y en presencia de un catalizador de níquel. Este método único en el mundo y del que el grupo poseía la patente, fue una de las principales razones del acelerado desarrollo de Hylsa.

Una vez conseguida la producción propia de materia prima para fabricar el acero, Hylsa creó la Compañía Minera Las Encinas S.A., cuyas minas están en el Estado de Colima, esta empresa extrae y procesa mineral de hierro para luego surtirlo a las acerías y convertirlo a fierro esponja gracias al proceso «HyL». En 1952, HYLSA comenzó sus operaciones mineras, y constituyó con ello su propia fuente de abastecimiento de minerales y completaba «hacia atrás» el circuito de integración de su empresa. En 1954, se adquirió la empresa Aceros Alfa Monterrey, S.A., que produce tubería de acero negro y galvanizada. Su producción inicial era de 900 toneladas mensuales, pero gracias a algunas ampliaciones que se hicieron, llegó a las 1,200 toneladas mensuales en 1958.

En 1957, se creó la primera Planta con Tecnología Hy|® Monterrey, comenzando así la diversificación «hacia delante» expandiendo los mercados e incursionando en la producción de tubería de acero negro y galvanizado, lo que dio lugar a la fundación de Aceros Alfa de México con el fin de fabricar varilla para refuerzo de concreto y posteriormente, a la formación del Grupo Acero Hylsa con las cuatro empresas existentes (Martínez,1984). La planta 1-M permitió la producción de 90 mil toneladas anuales.

En 1944 se creó en Monterrey la empresa Talleres Universales, S.A. (TUSA), cuyo objetivo era atender las necesidades de mantenimiento de la industria regiomontana. En 1954, TUSA se convirtió en una moderna fundición de piezas de hierro gris, hierro modular y aceros aleados. En 1943, se crea el Instituto Tecnológico y de Estudios Superiores de Monterrey (ITESM), abrió sus puertas con 350 estudiantes y 14 profesores (actualmente cuenta con 32 campus en todo el país). En 1945, establecen la Clínica de Sociedad Cuauhtémoc y Famosa, para dar servicio médico a los trabajadores de la empresa, (antes que existiera el IMSS). En esta misma década se inauguró la Colonia
Cuauhtémoc en Monterrey, se entregaron 1,318 casas a colaboradores del grupo. Este hecho también se anticipó a la creación del INFONAVIT.

En México, la industria nacional pese a sus esfuerzos no logró instaurar un crecimiento hacia dentro, la sustitución de importaciones no había sido planeada adecuadamente para operar como un todo en cada una de sus etapas, por consiguiente el modelo entró en crisis. Empezó a surgir una nueva forma de acumulación que buscó cambiar la relación entre el Estado, el capital nacional y el capital extranjero, cuyo eje pasó de ser el comercio exterior a ser la producción de bienes de consumo, el modelo se conoció como el desarrollo estabilizador cuyo pilar fue el crecimiento de la producción estatal (Basañez, 1991).

\section{Los sesenta: maduración industrial y financiera} El desarrollo estabilizador mantuvo en sus características generales las premisas de la primera década de la industrialización, pero las reforzó a partir del establecimiento de un tipo de cambio estable, de una política muy favorable al capital privado, y de una actitud de apoyo restringido a la inversión extranjera que permitió el establecimiento de numerosas empresas de capital mixto, las cuales al contar con una parte de capital mexicano se beneficiaban de la protección que el gobierno brindaba a las empresas nacionales (Baena, 2005). Promovida por el gobierno de Kennedy en Estados Unidos, al amparo de la Alianza para el Progreso los capitales extranjeros fluyeron a México e impulsaron el crecimiento de las manufacturas. En este periodo las grandes corporaciones transnacionales fincaron sus sucursales en México.

Hylsamex en 1960 instala la Planta 2.M con una capacidad de 475 toneladas anuales. En 1962 adquirió minas a través de la empresa «Las Encinas». En 1963 adquiere la empresa Aceros de México, dedicada a la producción de varilla. En 1967, adquiere $37 \%$ de las acciones del Consorcio Benito Juárez-Peña Colorada, lo cual le permite garantizar el abasto adecuado de mineral de hierro; posee también las plantas necesarias para paletizar el mineral. En 1969 instala su tercera planta 3-M. En relación al proceso de producción de la planta Hylsa de Puebla: su materia prima viene de la mina del grupo en Colima de donde se obtiene el mineral, que se reduce (se elimina el oxígeno) en la planta de fierro esponja. El fierro esponja y cierta proporción de chatarra constituye la materia prima de la planta de Hylsa en Puebla. En la acería se funde este material en forma de lingotes. El lingote pasa al molino de laminación en donde se convierte en varilla o alambrón, cuyo proceso es un poco más sofisticado 
que el de varilla. Se dobla y pasa a embarque (Pozas, 1994).

\section{Los setenta: la formación de los grupos industriales}

En México, el proceso de industrialización y la política proteccionista del Estado, orientada a impulsar la sustitución de importaciones, conllevó a la formación de grupos del sector privado nacional. Las grandes empresas de Monterrey formaron grupos industriales hasta llegar a constituir grandes corporativos. Entre 1970 y la crisis de 1982, se constituyó en Monterrey en términos formales, un importante número de conglomerados, gracias a los mecanismos organizativos previos que se venían experimentando desde los años treinta y la capacidad financiera y acelerada por lo signos de agotamiento que presentaba el modelo proteccionista o sustitutivo de importaciones. En México, la práctica de inversión diversificada originada a fines del siglo XIX, se constituyó en una estrategia empresarial que buscaba compensar las limitaciones sectoriales, regionales y sociales de un mercado interior de lento crecimiento, dejando de lado la integración esencialmente vertical.

El Estado contribuyó a incentivar la reestructuración a través de estímulos fiscales que se formalizaron en la Ley de Sociedades de Fomento, promulgada en junio de 1973. Esta Ley concedía subsidios para auspiciar la integración de empresas en grupos denominados unidades de fomento (Cerutti, 2000). Las dos facultades (subsidios fiscales) que otorgaba el decreto eran: a) Compensar utilidades de empresas del grupo con pérdidas de otras cumpliendo con el requisito de que las utilidades sobrantes fueran reinvertidas. Si estas utilidades eran reinvertidas en un plazo no mayor de 30 días, entonces quedaban exentas $100 \%$ del pago de los impuestos respectivos; b) Comprar acciones de empresas, invertir capital en ellas y venderlas posteriormente por medio de la Bolsa de Valores, quedando exentas totalmente de los impuestos respectivos (Basave,1996).

Se alentó así, la creación de las mayores «empresas tenedoras», es decir empresas controladoras (holding) que consolidaron resultados económicos financieros y fiscales. La empresa «holding» tiene diferentes funciones que puede resumirse en términos generales, en: 1) permitir el control de las acciones de otra u otras empresas; 2) controlar el aspecto operacional o de coordinación de las actividades empresariales; y 3) resolver los problemas de la acción empresarial. Estas funciones pueden ser desarrolladas por la empresa al mismo tiempo o no. Existen diferentes tipos de «holding» según las necesidades de los empresarios, éstas pueden ser «holding» de grupo, personales, mixtas (Cordero y Santín, 1977).

En el proceso de centralización de capital que desplegaron los grandes corporativos, los objetivos fueron distintos, en algunos casos para alcanzar una mejor integración de sus procesos productivos, en otros para aumentar su control oligopólico en sus respectivos mercados lo que llevó a la compra de empresas competidoras de gran tamaño, y en varios más con el objeto de diversificarse y participar en industrias intensivas en trabajo, buscando elevar la tasa de ganancia grupal de aquellas empresas que participan tradicionalmente en industrias intensivas de capital.

Una estrategia de las grandes empresas para captar capitales, es suscribirse en la Bolsa de Valores, con la colocación de acciones captan recursos de pequeños y grandes ahorradores, quienes participan así en la propiedad de las compañías. Las empresas adquieren una buena parte de su capital de esta manera y distribuyen las utilidades por medio de sus dividendos. Entre las medidas adoptadas para estimular la bolsa se registran en 1975 las modificaciones a la Ley del Mercado de Valores, cuyo propósito fue fusionar las bolsas de valores de México, Guadalajara y Monterrey en un organismo de carácter nacional denominado Bolsa Mexicana de Valores (Cardero, 1982).

A partir de 1970, el volumen de las acciones en la bolsa de valores se fue incrementando aceleradamente, gracias a las modificaciones tanto de la Ley del Mercado de Valores, la Ley de Impuestos sobre la Renta y otras hechas por la Comisión Nacional de Valores. Muchos grupos de Monterrey, diversificaron de manera ostensible su base de operaciones e incursionaron con vigor en ramas como alimentos, banca, turismo y bienes raíces. Alfa se suscribe a la bolsa en 1978.

\section{El Grupo Monterrey}

Los grupos industriales Cervecería Cuauhtémoc, Alfa, Vidriera y Cydsa constituyen lo que generalmente se les denominó como el Grupo Monterrey (en la actualidad no existen como grupo). El criterio para su delimitación de cada subgrupo es la interrelación de sus empresas por medio de una que controla las acciones-empresas holding- y para englobar estos subgrupos con el grupo Monterrey, el criterio central es que aquéllos se han formado a través de la transferencia de una parte de los intereses de un subgrupo hacia la estructuración de otro. El Grupo Monterrey, se distinguió por su alto grado de dinamismo en cuanto al empleo de tecnología y al tipo de integración industrial; políticamente, por 
sus argumentos nacionalistas, industrialistas y autoritarios (Luna, 1986).

A este conglomerado también se le denominó Grupo Visa, por ser la empresa que controla las acciones, en los setenta se integró por unas 45 empresas. No obstante, que las empresas creadas por el Grupo Monterrey en distintos momentos del siglo, tuvieron su verdadero despunte modernizador e innovador con proyectos económicos en los años cuarenta, cuando se inicia la segunda etapa del desarrollo de la siderurgia y su presencia se hace indiscutible en toda la nación; es en esta etapa cuando se observa una mayor consolidación y expansión de sus grupos. Como un solo grupo, Carlos Martínez Assad (1984) entre otros puntos, observa lo siguiente:

- El momento de aparición de cada una de las empresas que conforman el Grupo Monterrey, respondió siempre a las tendencias generales del capitalismo y a las especificaciones de la economía nacional.

- El entendimiento y la relación económica de los distintos subgrupos que lo conforman están vinculados a la pertenencia a un mismo tronco familiar.

- La comunidad de intereses económicos con base en su similar situación material dentro de las diversas industrias que ocupa cada grupo es lo que da unidad y razón de existir al Grupo Monterrey.

- El conjunto de empresas que forma el Grupo Monterrey tiene un alto desarrollo económico, emplea tecnología moderna, sistemas de producción muy perfeccionados y por sus dimensiones cuantitativas aglutina empresas vinculadas al período capitalista de gran industria.

- En sus empresas predomina el capital nacional, razón que coadyuva a su mantenimiento y las singulariza de las empresas de otros grupos similares del sector de gran industria.

Entre 1974 y 1980, el Grupo Monterrey creció desmesuradamente, sus conglomerados del tipo de Alfa y Visa se clasificaron entre los primeros de México y América Latina (Alba, 1990).

Es muy importante señalar, que el llamado Grupo Monterrey (Ortiz, 2009), a la muerte de su fundador Eugenio Garza Sada se dividió en dos: el conjunto de empresas, alrededor de la Cervecería Cuauhtémoc que junto con Banca Serfín constituirían el Grupo Visa comandado por Eugenio Garza Lagüera; y el conjunto de empresas alrededor de la siderúrgica Hojalata y Lámina (HYLSA) y de las empresas Nylon de México y Fibras Químicas, quedando al frente Bernardo Garza Sada. Este último, se convertiría en el Grupo Industrial Alfa una vez que el gobierno federal en 1973 emitió un decreto para estimular fiscalmente la formación de holdings, que bajo el régimen de Sociedades de Fomento Industrial contribuyeran, según criterios cuantitativos preestablecidos, a la creación de nuevos empleos, a incrementar exportaciones, sustituir importaciones, crear nuevas empresas, mexicanizar empresas de capital extranjero, invertir en zonas de menor desarrollo económico, entre otros requisitos. $A$ este decreto se apegaron otros grupos como el propio Visa, por ello ya no son el Grupo Monterrey.

En el Grupo Monterrey existieron dos grupos financieros: el grupo Serfín (1972) y el grupo Banpaís (1974). El primero, directamente vinculado al conglomerado Cuauhtémoc y el segundo, al grupo del Vidrio. Los dos grupos practicaron toda clase de operaciones: depósitos y ahorro, financiera, de crédito hipotecario, fiduciarias y sumaron aseguradoras y almacenes de depósito. Es importante destacar en este ámbito de operaciones, las ligas del grupo Monterrey con otros grupos financieros importantes del país: Eugenio Garza Laguera, Presidente del grupo Cuauhtémoc figuró en los consejos de administración de los grupos Bancomer y Comermex; Bernardo Garza Sada, dirigente del grupo Alfa, estaba en el consejo de administración de la financiera Bancomer (1976-1977).

\section{ALFA: reestructuración, reconversión e integración vertical y adquisiciones}

El grupo incursionó en campos clave de la economía mexicana: minería, siderurgia, papel, medios de comunicación y turismo. En 1974 ALFA se constituye a partir de tres empresas: 1) Hojalata y Lámina (Acero); 2) Empaques de Cartón titán (empaque); y 3) Draco (minería) además de una participación minoritaria en Televisa (Televisión). Alfa se consideró como parte de los grupos prominentes que se dedicaban a la minería y controlaban una parte importante de la economía. Alfa es una empresa holding controladora de empresas industriales en áreas diversas: alimentos, autopartes, petroquímica, productos metálicos, resinas sintéticas, fibras artificiales y siderurgia.

El grupo Alfa se convirtió en el más agresivo inversor del periodo, centralizando a grandes empresas de 
diversos giros en un proceso rápido de diversificación que cubría múltiples ramas industriales: minerales de hierro y no ferrosos, lácteos y productos cárnicos, empaques de frutas y legumbres, celulosa, papel y cartón, resinas y plásticos, maquinaria y equipo, aparatos eléctricos, autopartes y materiales de construcción. Adicionalmente adquirió $25 \%$ de las acciones de la Compañía Televisa y mantenía asociaciones de diverso tipo con empresas extranjeras como Hitachi, Ford, Magnavox, Massey Ferguson y FUD (Mendoza, 1997).

El crecimiento explosivo del Grupo Alfa a partir de 1977 se explica por la convergencia de varios factores: el gobierno ofrecía toda clase de estímulos al capital privado para iniciar una etapa de crecimiento acelerado de la economía, Alfa era más proclive a una política de acercamiento más que de enfrentamiento con el Gobierno Federal y a seguir una estrategia de expansión más ambiciosa que la que había caracterizado al Grupo Monterrey apostando a la diversificación y a la integración vertical y horizontal.

Alfa se expandió invirtiendo en las ramas productivas definidas por el gobierno como prioritarias y que gozaban de estímulos, en ramas cuya producción fuese insuficiente para asegurar mercados futuros como el turismo y por ello en 1976 y 1977 Alfa adquirió $99 \%$ de Frahopa, sobre la cual organizó el grupo Casolar, especializado en bienes raíces y turismo (Hotel Casolar, Manzanillo, Colima). El conglomerado Hylsa era el principal productor privado, participaba con el $21.5 \%$ de la producción nacional de acero; y el segundo más importante si se consideran las empresas estatales. En este campo, Alfa participaba con el Grupo Ramírez, uno de los líderes en la industria automotriz, en la empresa Talleres Universales.

Dentro de la clasificación de los grupos económicos mexicanos más importantes respecto al valor de la producción, Cuauhtémoc e Hylsa conjuntamente, ocupan el primer lugar en este periodo (Luna). Hylsa ocupaba uno de los primeros lugares a nivel mundial en tecnología de reducción directa, que transforma el mineral de hierro en fierro esponja, producto que sustituye con ventaja a la chatarra en la producción de acero, así mismo desarrolló un nuevo proceso (Hyl III) que introdujo innovaciones importantes como el llamado lecho móvil, que abate los insumos, reduce costos e incrementa la calidad del producto final.

Hylsa estableció contratos de comercialización de su tecnología con firmas de ingeniería y construcción más importantes del mundo -Kawasaki Heavy Industries,
M.A.M. - G.H.H. Sterckrade, Pullman Swindell y Dravopara diseñar y construir plantas que tengan incorporada la tecnología Hyl. En 1973, el proceso «HyL» fue utilizado en forma comercial por primera vez fuera de México en la planta de Usina Siderúrgica de Bahía, S.A. en Brasil. Dicha planta, diseñada con la colaboración de los ingenieros del Grupo Hylsa inició con una capacidad para 225,000 toneladas al año de fierro esponja.

En 1975, Alfa inició una estrategia de crecimiento y diversificación en negocios de fibras sintéticas, petroquímicos y electrónicos. Se incorporan empresas como Nylon de México (Nylon Tech). Nylón de México es productora de hilos sintéticos (Likra, entre otros) asociada con Dupont empresa norteamericana pionera en la producción de fibras sintéticas. En 1975 adquiere Polioles (poliesteno, uretanos ${ }^{*}$ y glicoles).

La empresa Polioles utiliza tecnología de BASF en la elaboración de productos químicos, derivados del petróleo, destinados a la producción de fibras sintéticas, colchones y acojinamientos, calzados, y otros. En 1975, Alfa establece con Dupont la primera alianza estratégica con una empresa internacional. En 1977, los negocios se agrupan a través de tres divisiones: Acero, papel y empaque e industrias. Se adquiere Fibras Químicas (fibras poliéster ${ }^{\S}$ ) hoy AKRA POLYESTER.

En 1978 adquieren MEGATEK. Con Megatek se logra sustituir buena parte de las importaciones de motores que la industria nacional venía haciendo hasta esa fecha y busca reducir las dificultades inherentes a la importación y abastecimiento de maquinarias que considera además la demanda agregada surgida a raíz de los crecientes presupuestos de explotación petrolera. La participación del gobierno en los proyectos de bienes de capital se demostró con el crédito - de $\$ 186$ millones de pesos- otorgado a Megatek por el Fondo Nacional de Equipamiento Industrial (FONEI). En ese contexto, Megatek nació como una empresa consolidada mediante la participación de capital mexicano y japonés, para la fabricación de motores y generadores eléctricos de gran capacidad. El socio del grupo Alfa en la empresa es la Hitachi Ltd., de Japón, que poseía el $49 \%$ del capital y proporcionó la tecnología y quien es reconocido líder mundial en aislamientos, componente fundamental para la vida de un motor y que exportaba tradicionalmente el $35 \%$ de sus ventas. La asociación con Hitachi incluyó un convenio de asistencia técnica para los trabajadores mexicanos. Los principales clientes de Megatek eran las industrias de acero, cemento, papel, minería, así como Petróleos 
Mexicanos, y la Comisión Federal de Electricidad. La línea de productos de Megatek, comprende motores de inducción de 200 a 12,000 caballos de fuerza, motores sincrónicos de 200 a 600 HP y motores de corriente directa de 10 a 3,500 HP y generadores de corriente alterna con capacidad de 15 a 5,000 kilowatts de potencia.

La zona elegida para la planta ubicada en Villa de García, Nuevo León, a unos 30 kilómetros de Monterrey, se localizó de acuerdo a la clasificación gubernamental en un área prioritaria de inversión industrial y contó con estímulos fiscales considerables. En su fase inicial la planta contó con 225 obreros, 50 técnicos (13 de ellos japoneses) y 60 empleados, en un área de 5,500 metros cuadrados. La planta empezó a operar desde abril de 1979.

En 1978 se adquiere PTEROTEMEX, ese año, se amplían las operaciones en petroquímica y acero con la adquisición de PETROCEL (DMT) y LA FLORIDA. Petrocel utiliza tecnología de Hercofina para producir dimetil terftalato y acido tereftálico, insumos en la producción de fibras sintéticas. En todas estas industrias participan varias empresas de Alfa, como Akra quien aplica tecnología de Du Pont y Akzo en la producción de fibras sintéticas, Selther quien fabrica colchones y espuma de poliuretano utilizando tecnología de P.R.B: empresa belga, Pom, Terza y el Grupo Marina. Agromak recibe el apoyo tecnológico de Massey Ferguson Ltd., para producir tractores y enseres agrícolas. Draco utiliza tecnología de Inco en la explotación de minerales no ferrosos destinados a las industrias electrónica (en la que participa Alfa), petrolera y aeronáutica. De esta forma, al igual que en las industrias del acero y del papel, el Grupo Alfa sigue una marcada política de autoabastecimiento.

La división acero de Alfa no tenía galvanizadora propia, por ello en diciembre de 1979 se creó Galvak, mediante la fusión de dos empresas adquiridas previamente, La Florida en noviembre de 1978 y Acerozinc en diciembre de 1979. Hylsa provee a Galvak de 60\% del insumo básico (lámina negra) y el grupo Sidermex (paraestatal) el restante $40 \%$. Los proveedores del otro insumo zinc, son empresas del gobierno federal o privatizadas (Industria Minera México, Metalúrgica Mex-Peñoles, Zincamex). Alfa es el propietario de Galvak y al mismo tiempo, el proveedor principal del insumo básico y de parte del equipo mediante Makrotek.

En el campo de la celulosa y papel, parte del consumo nacional se cubría mediante importaciones, puesto que existía un déficit en la producción nacional de celulosa superior a 100 mil toneladas anuales. Alfa buscaba autoabastecerse de estos insumos por medio de la nueva planta de celulosa y papel de la empresa Celulósicos Centauro, ubicada en Durango. En marzo de 1979 por medio de Titán, Alfa compró $51.89 \%$ de Celulósicos Centauro. Alfa estableció con Proformex (empresa paraestatal) un contrato por 50 años para el suministro de madera, insumo básico para la producción de celulosa. El contrato incluye la posibilidad de transferir la madera a otras empresas de Alfa.

Centauro, poseía una flotilla de camiones y tractocamiones y colaboraba con Proformex en la extracción, así como el traslado de madera. El proyecto Centauro permitió a Alfa reducir costos de transporte, puesto que en una sola planta se produciría celulosa y papel. En 1979 se abren las puertas del Planetario ALFA.

Alfa creó en 1979 la empresa Atlax, con objeto de profundizar la integración vertical del sector acero al producir directamente bienes para el consumidor final (aceros especiales, grado herramienta) y no sólo los insumos básicos para fabricarlos. En 1979 Surge NEMAK. Se asocia ALFA con FORD Motor Co., para producir y exportar a Estados Unidos y Canadá, cabezas de motor de aluminio. Las fabrica para la propia Ford y para Chrysler, General Motors y Renault. En relación al proceso de producción: la planta es fundamentalmente una fundición (Pozas, 1994). Las operaciones de ALFA se extienden a la fabricación de maquinaria agrícola, motocicletas, forja y fundición, aparatos domésticos y aceros especiales.

En 1979, Hylsa participó como accionista mayoritario $60 \%$ junto con el consorcio español Duro-Felguera en la creación de la empresa Makrotek un ambicioso proyecto para fabricar en México bienes de capital destinados a las industrias siderúrgica, petroquímica, petrolera, electricidad, fertilizantes y cemento. Makrotek produciría equipos que requieren para su expansión Hylsa y subsidiarias, Atlax, Galvak y otras. El citado grupo español contaba con 80 años de experiencia en la fabricación de bienes de capital y era líder en España. La tecnología que pudiera utilizarse se obtendría mediante licencias de construcción de varias empresas internacionales como Kawasaki, L F Smidth, Electrowelt, Dravo, y otras. En el campo de la acería Alfa inició en 1980 un proyecto para la planta de Monterrey cuya meta era producir un millón 600 toneladas anuales, en 1981 la producción nacional llegó a 7.5 millones de toneladas, lo cual resultó insuficiente para satisfacer una demanda de 11 millones de toneladas. 
Tabla 1

Grupo Industrial ALFA

\begin{tabular}{|c|c|c|c|}
\hline Empresas industriales & Empresas industriales & Bienes raíces y turismo & Otras \\
\hline Hojalata y Lámina S.A. & M akros, S.A. & Casolar, S.A. & $\begin{array}{l}\text { Televisa S.A. (Participación } \\
25 \%)\end{array}$ \\
\hline Talleres Universales, S.A. & Industrial de México, S.A. & $\begin{array}{l}\text { Fraccionadora y Hotelera } \\
\text { del Pacífico, S.A. }\end{array}$ & $\begin{array}{l}\text { Televisión Independiente de } \\
\text { México, S.A. }\end{array}$ \\
\hline Grafo Regia, S.A. & $\begin{array}{l}\text { Técnica Papelera M exicana, } \\
\text { S.A. }\end{array}$ & $\begin{array}{l}\text { Cía. Operadora del } \\
\text { Pacífico de M éxico, S.A. }\end{array}$ & Televisión del Norte, S.A. \\
\hline Fierro Esponja, S.A. & Derivados Sintéticos, S.A. & Inmobiliaria Petrocel, S.A. & Televisión del Golfo, S.A. \\
\hline Aceros de M éxico, S.A. & Tabriz, S.A. & Hotel Las Hadas & Televisión de Puebla, S.A. \\
\hline $\begin{array}{l}\text { Hylsa de M éxico } \\
\text { (Hylsamex) }\end{array}$ & Cydsa Comercial, S.A. & $\begin{array}{l}\text { Promotora y Arrendadora } \\
\text { Industrial, S.A. }\end{array}$ & $\begin{array}{l}\text { Televisión Independiente de } \\
\text { Jalisco ,S.A. }\end{array}$ \\
\hline Las Encinas, S.A. & Pom, S.A. & $\begin{array}{l}\text { Inmobiliaria de Desarrollo } \\
\text { Industrial, S.A. }\end{array}$ & $1979-1980$ \\
\hline $\begin{array}{l}\text { Industrias Formacero, } \\
\text { S.A. }\end{array}$ & $\begin{array}{l}\text { Impulsora y Promotora Api, } \\
\text { S.A. }\end{array}$ & $\begin{array}{l}\text { Fraccionamiento } \\
\text { Península de Santiago, } \\
\text { S.A. }\end{array}$ & $\begin{array}{l}\text { Dinámica, S.A. (con } \\
\text { participación M inoritaria en } \\
\text { Televisa, S.A. ( } 25 \%)\end{array}$ \\
\hline $\begin{array}{l}\text { Constructora y } \\
\text { Desarrolladora del } \\
\text { Pacífico, S.A. }\end{array}$ & $\begin{array}{l}\text { Industrial y Comercial Río } \\
\text { Lerma, S.A. }\end{array}$ & La Gran Aventura, S.A. & $\begin{array}{l}\text { Teleproductora } \\
\text { Independiente de M éxico, } \\
\text { S.A. }\end{array}$ \\
\hline Placa y Lámina, S.A. & Europom, S.A. & Inmobiliaria Amsa, S.A. & $\begin{array}{l}\text { Fomento de Televisión } \\
\text { Nacional, S.A. }\end{array}$ \\
\hline M ateriales y Aceros, S.A. & $\begin{array}{l}\text { Acojinamientos Selther, } \\
\text { S.A. } \\
\text { Alfa Industrias División } \\
\text { Petroquímica, S.A. }\end{array}$ & Inmobiliaria Pirámide, S.A. & ALIMENTOS \\
\hline La Florida, S.A. & Vistar, S.A. & M INERÍA & ELECTRONICA \\
\hline Nylon de México, S.A. & $\begin{array}{l}\text { Servicios Administradores, } \\
\text { S.A. }\end{array}$ & Draco, S.A. & Philco, S.A. \\
\hline Polioles, S.A. & $\begin{array}{l}\text { Administración de } \\
\text { Operación y Asesoría, S.A. }\end{array}$ & $\begin{array}{l}\text { Consorcio M inero Peña } \\
\text { Colorada }(28.5 \%)\end{array}$ & Admiral de M éxico, S.A. \\
\hline $\begin{array}{l}\text { Celulósicos Centauro, } \\
\text { S.A. de C.V. }\end{array}$ & Industrial Alfa, S.A. & Minas Draco, S.A. & $\begin{array}{l}\text { Construcciones Electrónicas, } \\
\text { S.A. de C.V. (M agnavox) }\end{array}$ \\
\hline Fibras Químicas, S.A. & Acustec, S.A. & Minera Draco, S.A. & Electrónica Aural, Ltd. \\
\hline Petrocel, S.A. & Vektor,S.A. & & Admiral Trade Co. \\
\hline M egatek, S.A. & Acermex, S.A. & & \\
\hline Pterotemex & $\begin{array}{l}\text { Componentes y M ontajes, } \\
\text { S.A. }\end{array}$ & SERVICIOS & HOLDING \\
\hline Corporación Hylsa, S.A. & M otocicletas Carabela, S.A. & $\begin{array}{l}\text { Ingeniería y Servicios } \\
\text { Integrados, S.A. }\end{array}$ & Alfa, S.A. \\
\hline Galvak, S.A. & Bicicletas Windsor, S.A. & $\begin{array}{l}\text { Dinámica Industrial } \\
\text { Monterrey, S.A. }\end{array}$ & \\
\hline M egatek, S.A. & Tubos Amsa, S.A. & Técnica Industrial, S.A. & \\
\hline Atlax, S.A. & M otomex, S.A. & & EMPAQUES \\
\hline $\begin{array}{l}\text { Industrias Gama de } \\
\text { M onterrey, S.A. }\end{array}$ & $\begin{array}{l}\text { Corporación } \\
\text { Industrializadota de } \\
\text { M aderas, S.A. }\end{array}$ & & $\begin{array}{l}\text { Empaques de Cartón Titán, } \\
\text { S.A. }\end{array}$ \\
\hline $\begin{array}{l}\text { Ferrominera Mexicana, } \\
\text { S.A. }\end{array}$ & $\begin{array}{l}\text { Aceptaciones } \\
\text { M assey Ferguson, S.A. }\end{array}$ & & $\begin{array}{l}\text { Empaques y Cartón } \\
\text { Corrugado, S.A. }\end{array}$ \\
\hline $\begin{array}{l}\text { Hylsa Internacional Corp. } \\
\text { M assey Ferguson, S.A. }\end{array}$ & $\begin{array}{l}\text { Implementos Agrícolas } \\
\text { M exicanos, S.A. }\end{array}$ & & Servi-Empaque, S.A. \\
\hline
\end{tabular}

Fuente: elaborado a partir de la información que presenta Salvador Cordero y Rafael Santín en su obra Los Grupos Industriales: una nueva organización económica en México, El Colegio de México, 1977, donde analiza cincuenta grupos industriales de control privado nacional e información de las páginas Web de las empresas. Entre 1979 - 1980 se registran en la Revista Expansión 60 empresas más. 
En 1980, adquirió empresas que dieron origen a Sigma Alimentos y adquirió Terza. Ese año ALFA incursiona en alimentos, se adquieren las empresas que dieron origen a SIGMA. Alfa adquiere a Grupo Brener, el negocio de carnes frías fue establecido en 1939 por la familia Brener de quienes Alfa adquirió sus principales marcas incluyendo Fud, San Rafael, Iberomex, Chimex y Viva. En 1980, el número de asociaciones y alianzas estratégicas de ALFA se había ampliado, incluyendo a empresas como AKZO, BASF, HITACHI, FORD, KAWASAKI y SIEMONS.

En 1981, se interrumpe el crecimiento, los problemas económicos en México iniciados en este año, afectaron las finanzas de ALFA. Se cancelaron proyectos y se redujeron gastos de administración, además se inició un proceso de reestructuración de pasivos, consolidación de operaciones y desinversiones. La crisis de 1982 puso a prueba la capacidad de adaptación y supervivencia de los grandes corporativos de Monterrey, el grupo más endeudado fue el grupo Industrial Alfa.

\section{CONCLUSIONES:}

- El fuerte sello de rasgos regionales y familiares que tuvieron los grupos económicos surgidos desde el siglo XIX hasta las postrimerías de la Revolución de 1910 puede atribuirse a diversos factores: el aislamiento de ciertas áreas, la distancia de las estructuras de poder, las desigualdades en el proceso de integración de algunas zonas geográficas. En la evolución del capitalismo tardío, es en el porfiriato donde se encuentran los rudimentos de la industrialización del país, las empresas industriales que le dieron dinamismo nacieron monopólicas.

- Una amplia porción del norte desempeñó un papel fundamental en la formación e integración del mercado nacional: a) porque el norte comenzó a especializarse en producciones para el mercado interior antes de la llegada del ferrocarril; $b$ ) por haber concentrado una vasta proporción del tendido de los ferrocarriles, que lo unían a los grandes sistemas de Texas y el resto del territorio estadounidense, c) por el efecto productivo que ocasionaron las demandas de minerales y metales de la segunda revolución industrial.

- En relación al desarrollo de las empresas, se observa que hasta la década de los años cincuenta, los mecanismos más importantes de crecimiento fueron la expansión de las plantas y el establecimiento de nuevas instalaciones. De los sesenta en adelante, se hicieron más comunes las adquisiciones y las fusiones. El crecimiento por medio de las asociaciones, las adquisiciones y fusiones, llevó a un control oligopólico del mercado interno. Las corporaciones reunidas alrededor del Grupo Monterrey, se expandieron y diversificaron: en ciertos momentos se ramificó, ya sea para compensar fallas de mercado y escasez de la demanda, para contrarrestar los ciclos económicos sectoriales, para desplazarse hacia sectores más redituables y dinámicos.

- Entre 1960 y 1980 los vínculos con el capital extranjero adquirieron una mayor importancia para la expansión y la modernización tecnológica de los grandes grupos mexicanos. Acentuado por el modelo protegido, crecieron desmedidamente los niveles de concentración del capital en todos los sectores de la economía nacional, fundando un conjunto de grandes empresas privadas en los sectores más dinámicos de la economía. La centralización del capital se detecta de 1974 a 1982, una centralización diferenciada, una industrial (19741979) que se trató de una estrategia de integración vertical y horizontal; y una bancaria (1974-1982) que produjo un proceso de reposicionamiento de capitales.

- Finalmente, entre 1970 y la crisis de 1982 que se constituyó en Monterrey, en términos formales, un importante número de conglomerados 0 corporativos, tales como Alfa. En su enorme mayoría, sus raíces se remontan a las empresas pioneras de principios de siglo o empresa-madre que aparecieron entre 1930 y 1950. Los mecanismos organizativos previos- que se venían experimentado desde los años treinta- y una densa capacidad financiera favorecieron este fenómeno, aclarado además por los signos de agotamiento que presentaba el modelo proteccionista o sustitutivo de importaciones. El Estado contribuyó a fomentar la reestructuración empresarial. 


\section{REFERENCIAS}

Alba, V. C.(1990). Las regiones industriales y los empresarios de México. Revista Mexicana de Sociología, 52(2), abriljunio, p. 29

Baena, P. G.(2005). Estructura socioeconómica de México. México: Publicaciones Cultural.

Basave, K. (1996). Los Grupos de capital financiero en México, 1974-1995. México, p. 85.

Basáñez, M. (1991). La lucha por la hegemonía en México 19681990. México: Ed. Siglo XXI. Pp.169-170.

Cardero, M. E. y Quijano, J. M. (1982). Expansión y estrangulamiento financiero 1978-1981. Revista Economía Mexicana, No. 4, p. 174.

Carr, B. (1973). Las peculiaridades del norte mexicano, 18801927: ensayo de interpretación. Revista Historia Mexicana, XXII(3) enero-marzo, el Colegio de México, p. 323.

Cerutti, M.(1982). La formación de capitales preindustriales en Monterrey (1850-1890). Las décadas previas a la configuración de una burguesía regional. Revista Mexicana de Sociología, XLIV(1) enero-marzo, p. 81.

(1992). Burguesía, capitales e industria en el norte de México, Monterrey y su ámbito regional (1850-1910). México: Alianza Editorial.

(2000). Propietarios, empresarios y empresa en el norte de México. México: Siglo XXI.

Cerutti, M. y Valdaliso, J.M. (2003). Monterrey y Bilbao (18701914). Empresariado, industria y desarrollo regional en la periferia. Revista Historia Mexicana, LII(208) 4, abril-junio, El Colegio de México, p. 909.

Cordero S. y Santín (1977). Los Grupos Industriales: una nueva organización económica en México. El Colegio de México, p. 19.

Garrido, C. y W. Peres (1998). Las grandes empresas y grupos industriales latinoamericanos en los años noventa” en Wilson Peres (Coord.) Grandes Empresas y Grupos Industriales Latinoamericanos, Siglo XXI CEPAL México, p. 19.

Hamilton, N. (1983). México: los límites de la autonomía del Estado, Apéndice B «El grupo de inversión Garza Sada. Orígenes de los grupos Cuauhtémoc y Vidriera. México: Ediciones Era.

Leal, J. F. (1972). El siglo diecinueve mexicano, el estado y las clases sociales 1821-1854. Revista Mexicana de Ciencias Políticas, XVIII(70) octubre-diciembre, México, p. 6.

Luna, L. M. (1986). El Grupo Monterrey en la economía mexicana, en Julio Labastida (Compilador) Grupos Económicos y Organizaciones Empresariales en México, Alianza Editorial Mexicana, UNAM, México, p. 263.

Marichal, C. (1997). Avances recientes en la historia de las grandes empresas y su importancia para la historia económica de México» en Carlos Marichal y Mario Cerutti
(Comp.) Historia de las Grandes Empresas en México 18501930, Universidad Autónoma de Nuevo León FCE México, p. $25-26$.

Martínez, A. C. ( 1984). Auge y decadencia del grupo Monterrey. Revista Mexicana de Sociología, XLVI(2) abril-junio.

Marx, C. (1975). El capital. Tomo I, Vol. 3 Siglo XXI, México, pp. 942-943.

Mendoza, A.M. (1997). Alfa, uno de los grupos económicos más importantes de México (Tesis profesional). Facultad de Economía-UNAM, México 1997, pp.32-40.

Periódico Oficial del Estado de Nuevo León, 3 de diciembre de 1927.

Periódico Oficial, 16 de mayo de 1934.

Pinto, A. (1991). América Latina: una visión estructuralista. UNAM, México, pp.242-243.

Pozas, M. Á.(1994). Modernización de la industria y relaciones de trabajo, Fundación Friedrich Ebert. EI Colegio de la Frontera Norte, México, p. 191.

Puga, E. C. y Torres M. D. (1995). México: la modernización contradictoria. México: Alambra Mexicana, pp.23-24.

Revista Expansión No. 274, Año XI, Vol. XI, pp. 44-49.

Revista Expansión, No. 257, 19 de enero de 1979.

Revista Expansión 22 agosto 1979.

Revista Expansión 20 agosto 1980.

Sada, C. G. (1973) Entrevista, "Gracias a las Corcholatas» en Revista Expansión, 19 de septiembre.

Semo, E. (1973). Historia del Capitalismo en México. Los orígenes 1521-1723. México: Era, pp. 232-236.

Vellinga, M. (1988). Desigualdad, poder y cambio social en Monterrey. México: Siglo XXI.

www.alfa.com.mx 


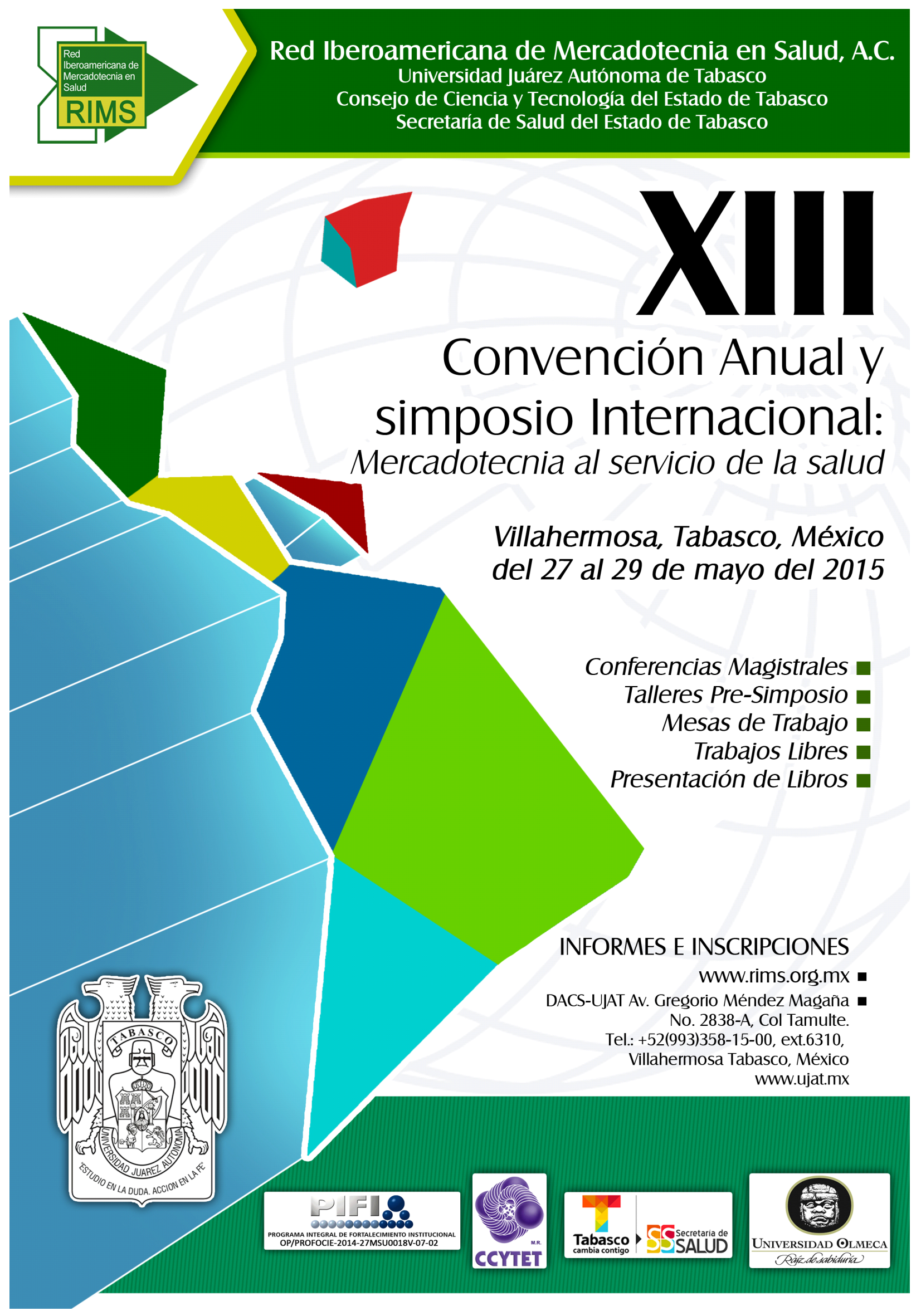

